\title{
Atrioventricular Block: Natural History After Permanent Ventricular Pacing
}

ARTHUR B. SIMON, MD, FACC

ALAN E. ZLOTO, BS, MPH

Ann Arbor, Michigan
From the Department of Internal Medicine (Section of Cardiology), University of Michigan Medical Center, and the Department of Epidemiology, School of Public Health, University of Michigan, Ann Arbor, Michigan. This paper was supported in part by a grant from the Michigan Heart Association, Southfield, Michigan, for fulfillment in part of the degree of Master in Public Health to Mr. Zloto, 1976. Manuscript received May 31, 1977; revised manuscript received August 22, 1977, accepted September 1, 1977.

Address for reprints: Arthur B. Simon, MD, Heart Station, University Hospital, 1405 East Ann Street, Ann Arbor, Michigan 48109.
The preimplantation status, postimplantation morbidity and causes of late mortality were summarized for 246 patients who underwent pacing for atrioventricular (A-V) block at the University of Michigan for the 14 years from 1961 to 1974 . The survival rate at 1,5 and 10 years was 88, 61 and 49 percent, respectively. Risk of death was greatest among patients with antecedent ischemic or hypertensive heart disease or congestive heart failure in the perlod before pacemaker implantation, patients older than 74 years at initlal implantation and those receiving a pacemaker before 1965. Forty-two percent of the 109 deaths were related to apparent progression of underlying cardlac disease. Pacing system malfunction was a contributing documented cause of only 3 deaths. Even with permanent pacemaker implantation, patients with A-V block have a higher age-specific mortality rate than the general U.S. population. Survival improved steadily over the period of study. This change is attributed to apparent improvements in treatment of cardiovascular disease including more effective treatment of congestive heart fallure and valve replacement for selected patients as well as elimination of immediate postoperative mortality.

Permanent ventricular pacing has been the recognized treatment for atrioventricular (A-V) block for more than 15 years. Previous reports ${ }^{1-4}$ have documented the continued morbidity and mortality in patients with A-V block who have received pacemakers. This report reviews the status of such patients to determine the natural history of this disorder after permanent pacemaker implantation, the causes of late morbidity and mortality and the changes in mortality that occurred during the follow-up period. Survival of this population group was also compared with that of the U.S. population matched for age, race and sex.

\section{Methods}

The records of all adult patients who received permanent pacemakers at the University of Michigan Medical Center from 1961 through 1974 were reviewed. Many of the patients have been the subject of previous reports from this institution. 4-11 Since 1965, all patients have been followed up in a pacemaker clinic. Data on the history, clinical course, specific arrhythmias seen and follow-up findings were transferred to computer tape. Survival curves were determined with the life table method ${ }^{12,13}$ utilizing the Michigan Interactive Data Analysis System (MIDAS) ${ }^{14}$ and the Interactive Graphic Survival Analysis System (IGSAS). ${ }^{15}$ For each patient survival time was calculated from the date of the first pacemaker implantation until death or the end of the observation period, March 1, 1976. For the one patient who was lost to follow-up, survival was calculated from the date of implantation to the date of last follow-up.

Patient selection: The study population consisted of 246 adult patients who received their initial pacemaker at the University of Michigan Medical Center for an A-V conduction disturbance during the years specified. Patients with bifascicular block and syncope, but without documentation of complete A-V block, and two patients with atrial fibrillation and advanced second degree block 
were also included. Fifty-seven patients who underwent pacing for sinus node disease, hypersensitive carotid sinus syndrome or drug-resistant ventricular tachycardia, $20 \mathrm{pa}$ tients in the pediatric age group (14 years or less) and 19 patients who received their initial pacemaker elsewhere were excluded.

Derivation of survival data: The Breslow's generalized Kruskal-Wallis Test was utilized to determine if the survival distribution differed across strata for any single preimplantation variable. ${ }^{16}$ The survival data for the "control" U.S. population were derived from abridged life tables for race and sex found in reports of the vital statistics of the United States from 1962 to $1973.17,18$ Each individual study patient was matched to a life table specific to year of initial implantation, sex and race. A $t$ statistic was then computed to test the null hypothesis that the mean of the differences between the survival times of the patients and control subjects was zero. This was computed for the entire population and for each age stratum used (less than 65,65 to 74 and more than 74 years).

Classification of heart disease: The etiology of the heart disease associated with the conduction disturbance was inferred from the available clinical data. Arteriosclerosis was accepted as a cause of disease only if the patient had a myocardial infarction documented by enzyme or electrocardiographic criteria or definite angina pectoris. Rheumatic heart disease was considered a cause if the patient had cardiac valve disease, usually of both the aortic and the mitral valves, a positive history of acute rheumatic fever or pathologic evidence of it at the time of operation or autopsy. Isolated aortic valve disease was considered a cause when appropriate physical findings were accompanied by a negative history for rheumatic fever and no pathologic changes of rheumatic heart disease at operation or autopsy were found. Patients with a faint systolic ejection murmur alone were not classified in this category. Patients with calcific aortic stenosis and idiopathic aortic insufficiency, as well as those with aortic valve disease secondary to other disease processes (for example, ankylosing spondylitis), were included in this category. Patients were judged to have cardiomyopathy if they had severe generalized cardiomegaly with or without congestive heart failure before pacing and if no other apparent cause for the cardiomegaly was evident. Congenital heart disease was diagnosed on the basis of the usual clinical, cardiac catheterization and surgical criteria. Hypertensive heart disease was defined as radiographic cardiomegaly or evidence of left ventricular hypertrophy in the electrocardiogram combined with repeated recordings of blood pressure greater than $160 / 90 \mathrm{~mm} \mathrm{Hg}$.

When a patient had more than one form of heart disease, the apparent dominant etiology at the time of initial implantation was utilized for classification purposes. Patients whose condition did not satisfy the criteria for any of the categories cited were classified under "idiopathic." Patients in this category were free of hypertension, had no antecedent myocardial infarction or angina pectoris, had no significant murmurs and had a normal heart size or only slight cardiomegaly without congestive heart failure at implantation.

Determination of cause of death: The method for determining the cause of death was similar to that previously described. ${ }^{19}$ Details concerning the circumstances of death were obtained by interviewing the patient's physician, family members or other informed witnesses. Hospital, autopsy and medical examiner records and terminal electrocardiograms were obtained whenever feasible. Available pacing system components were retrieved for electronic analysis after death whenever possible.

Sudden death was defined as death within 1 hour of the onset of symptoms ${ }^{20}$; for most of the patients included here, death was apparently instantaneous or nearly so. Definite congestive heart failure was diagnosed on the basis of examination of available records and utilization of the criteria of McKee et al. ${ }^{21}$ Two or more of the following signs and symptoms were required: exertional dyspnea, paroxysmal nocturnal dyspnea, neck vein distension, cardiomegaly, rales, pulmonary edema, third sound gallop or positive hepatojugular reflux or weight loss of $4.5 \mathrm{~kg}$ or more in response to treatment. The minor criteria of McKee were not utilized.

Type of pacemaker implant: From 1961 to 1965, every patient received an epicardial lead implant through a left or anterior thoracotomy under general anesthesia. Since 1965

\section{TABLE I}

Major Symplomatic Disease States Before Initial Pacemaker Implantation Correlated With Year of Implantatlon *

\begin{tabular}{|c|c|c|c|c|c|c|c|c|c|c|}
\hline \multirow[b]{2}{*}{ Diagnosis } & \multicolumn{2}{|c|}{$\begin{array}{c}1961-64 \\
\text { (no. }=51 \text { ) }\end{array}$} & \multicolumn{2}{|c|}{$\begin{array}{c}1965-69 \\
(\text { no. }=103)\end{array}$} & \multicolumn{2}{|c|}{$\begin{array}{c}1970-74 \\
\text { (no. }=92 \text { ) }\end{array}$} & \multicolumn{3}{|c|}{$\begin{array}{c}\text { Total } \\
\text { (no. }=246 \text { ) }\end{array}$} & \multirow{2}{*}{$\begin{array}{c}P \\
\text { Value }\end{array}$} \\
\hline & no. & $\%$ & no. & $\%$ & no. & $\%$ & & no. & $\%$ & \\
\hline $\begin{array}{l}\text { Cardiovascular } \\
\text { Angina pectoris } \\
\text { Myocardial infarction } \\
\text { Congestive failure }\end{array}$ & $\begin{array}{r}4 \\
6 \\
17\end{array}$ & $\begin{array}{r}7.8 \\
11.8 \\
33.3\end{array}$ & $\begin{array}{l}10 \\
11 \\
36\end{array}$ & $\begin{array}{r}9.7 \\
10.7 \\
35.0\end{array}$ & $\begin{array}{l}15 \\
25 \\
35\end{array}$ & $\begin{array}{l}16.3 \\
27.2 \\
38.0\end{array}$ & $\begin{array}{l}29 \\
42 \\
88\end{array}$ & $\left.\begin{array}{l}11.8 \\
17.1 \\
35.8\end{array}\right\}$ & & $<0.005$ \\
\hline $\begin{array}{l}\text { Systolic hypertension } \\
\text { Diastolic hypertension } \\
\text { Peripheral (arterial) vascular disease }\end{array}$ & $\begin{array}{r}22 \\
11 \\
4\end{array}$ & $\begin{array}{r}43.1 \\
21.6 \\
7.8\end{array}$ & $\begin{array}{l}54 \\
12 \\
12\end{array}$ & $\begin{array}{l}52.4 \\
11.7 \\
11.7\end{array}$ & $\begin{array}{r}51 \\
19 \\
9\end{array}$ & $\begin{array}{r}56.0 \\
20.9 \\
9.8\end{array}$ & $\begin{array}{r}127 \\
42 \\
25\end{array}$ & $\begin{array}{l}51.8 \\
17.1 \\
10.2\end{array}$ & & \\
\hline $\begin{array}{l}\text { Cerebrovascular disease (including transient ischemic } \\
\text { attacks, stroke, embolism, subdural } \\
\text { hemorrhage, organic brain syndrome) }\end{array}$ & 5 & 9.8 & 10 & 9.7 & 17 & 18.5 & 32 & 13.0 & & \\
\hline $\begin{array}{l}\text { Syncope } \\
\text { Cardiomegaly (definite) }\end{array}$ & $\begin{array}{l}43 \\
23\end{array}$ & $\begin{array}{l}84.3 \\
46.9\end{array}$ & $\begin{array}{l}81 \\
47\end{array}$ & $\begin{array}{l}78.6 \\
46.1\end{array}$ & $\begin{array}{l}50 \\
38\end{array}$ & $\begin{array}{l}54.3 \\
41.3\end{array}$ & $\begin{array}{l}174 \\
108\end{array}$ & $\begin{array}{l}70.7 \\
44.4\end{array}$ & & $<0.001$ \\
\hline $\begin{array}{l}\text { Other } \\
\text { Diabetes mellitus } \\
\text { Renal disease } \\
\text { Obesity }\end{array}$ & $\begin{array}{l}12 \\
12 \\
10\end{array}$ & $\begin{array}{l}23.5 \\
22.5 \\
19.6\end{array}$ & $\begin{array}{l}27 \\
18 \\
27\end{array}$ & $\begin{array}{l}26.2 \\
17.5 \\
26.2\end{array}$ & $\begin{array}{l}19 \\
26 \\
38\end{array}$ & $\begin{array}{l}20.7 \\
28.3 \\
41.3\end{array}$ & $\begin{array}{l}58 \\
56 \\
75\end{array}$ & $\begin{array}{l}23.7 \\
22.8 \\
30.3\end{array}$ & & $<0.025$ \\
\hline $\begin{array}{l}\text { Obstructive lung disease } \\
\text { Cancer }\end{array}$ & $\begin{array}{l}5 \\
4\end{array}$ & $\begin{array}{l}9.8 \\
7.8\end{array}$ & $\begin{array}{l}17 \\
11\end{array}$ & $\begin{array}{l}16.5 \\
10.7\end{array}$ & $\begin{array}{r}10 \\
8\end{array}$ & $\begin{array}{r}10.9 \\
8.7\end{array}$ & $\begin{array}{l}32 \\
23\end{array}$ & $\begin{array}{r}13.0 \\
9.3\end{array}$ & & \\
\hline
\end{tabular}

* There is no significant difference over the 14 year period of the study as to patient selection except as specified. Most patients had multiple conditions. 


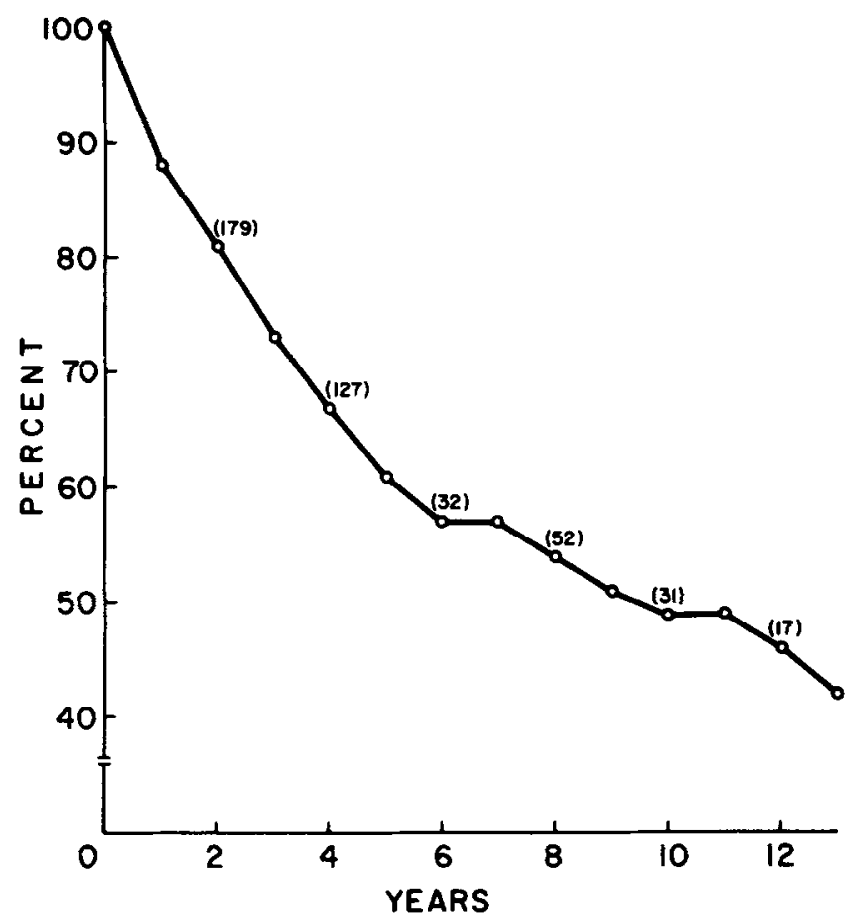

FIGURE 1. Survival after initial pacemaker implantation. The numbers in parentheses beside each 2 year point signify the number of patients remaining at each interval.

two thirds of the patients have had the transvenous approach as the implantation method of choice. During the follow-up period pacing was performed with General Electric, Medtronic, Cordis or CPI pacing systems. Patients received from 1 to 12 pulse generators during the follow-up period.

\section{Results}

The 246 adult patients who received a permanent ventricular pacemaker for A-V heart block consisted of 159 men and 87 women; only 8 were nonwhite. The mean age at initial implantation was 66 years (range 16 to 89 ); 27 percent were 75 years of age or older and 35 percent were less than 65 years.

Before pacemaker implantation, these patients had a large prevalence of symptomatic cardiovascular disease and other illnesses as well (Table I). Diabetes mellitus was present in 24 percent and symptomatic chronic obstructive lung disease in 13 percent; 9 percent

\section{TABLE \|}

Survival of Paced Population Over the Time of the Follow-up Perlod Compared With Survival of Age-SexRace-Matched Control Subjects from the U.S. Population

\begin{tabular}{ccccc}
\hline Age (yr) & $\begin{array}{c}\text { Patients } \\
\text { (no.) }\end{array}$ & $\begin{array}{c}\text { Observed } \\
\text { Survival } \\
\text { (mo) }\end{array}$ & $\begin{array}{c}\text { Expected } \\
\text { Survival } \\
\text { (mo) }\end{array}$ & $\begin{array}{c}P \\
\text { Value }\end{array}$ \\
\hline$<65$ & 86 & 70 & 83 & $<0.002$ \\
$64-74$ & 93 & 57 & 73 & $<0.002$ \\
$\geqslant 75$ & 67 & 45 & 59 & $<0.002$ \\
All ages & 246 & 58 & 73 & $<0.0001$ \\
\hline
\end{tabular}

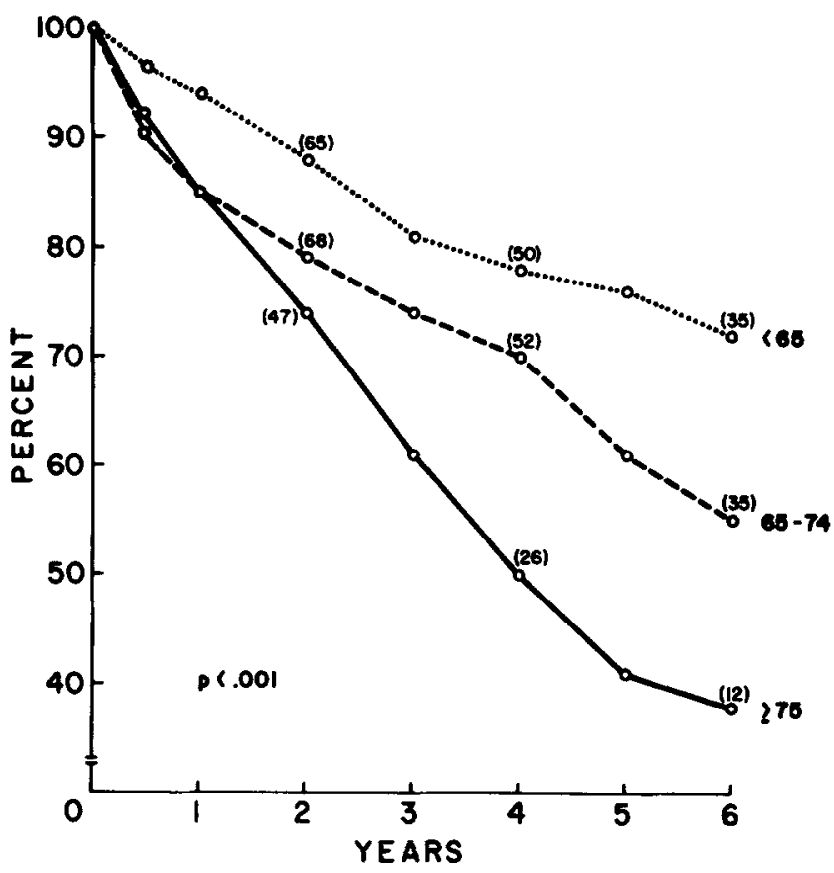

FIGURE 2. Survival after initial pacemaker implantation correlated with age at entry. Age as a predictor of mortality was highly significant, but when analyzed separately patients in the intermediate age range were not significantly different from the very elderly $(P=0.15)$.

had a history of major organ malignant neoplasm and 30 percent were obese. A prior myocardial infarction could be documented in only 17 percent; congestive heart failure was present in 36 percent. Transient cerebral ischemic attacks, previous stroke and arteriosclerotic peripheral vascular disease were also common. With the exception of obesity, there was no significant difference in prevalence of any chronic disease state in patients selected for pacing over the period of the study (Table I).

\section{Survival}

The survival rate of the entire group was 61 percent at 5 years and 49 percent at 10 years. The highest mortality rate (12 percent) occurred in the first year (Fig. 1). Survival was highly correlated with age at initial implantation (Fig. 2). Patients under age 65 had a 5 year survival rate of 75 percent, whereas only 40 percent of those over age 74 lived more than 5 years. Patients in the intermediate age group (65 to 74 years) had a 5 year survivorship of 61 percent $(P=0.002)$. For each age group the patients with pacing had a shorter survival time than the general population (Table II). Mean survival time for all patients with pacing was 58 months compared with an expected survival time of 73 months $(P<0.001)$.

Mortality and year of initial implantation: Mortality also correlated with the year of initial implantation. In Figure 3 the study group is divided into three subgroups stratified by the year of initial pacemaker implantation-1961 to 1964, 1965 to 1969 and 1970 to 1974. Survival improved progressively in each interval, 


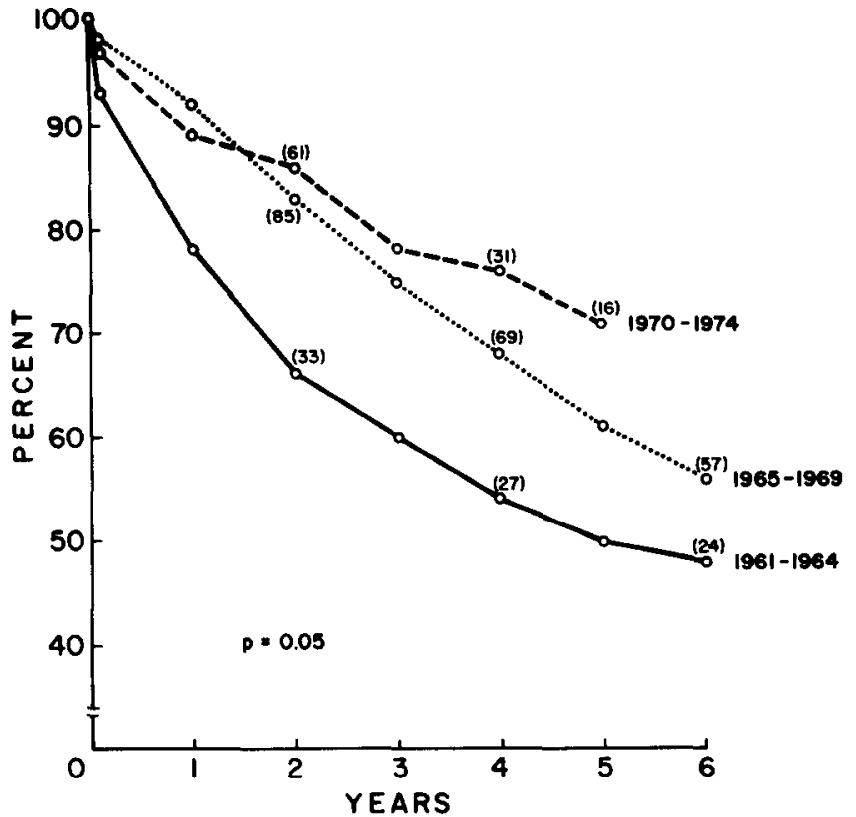

FIGURE 3. Survival after implantation correlated with year of implantation. The excessive first year mortality in the 1961 to 1964 period is due in part to perloperative mortality associated with epicardial implants used exclusively in that time period. When analyzed separately, the 1965 to 1969 group did not differ significantly from the 1970 to 1974 group $(P<0.20)$.

with 5 year survival rates of 50,61 and 71 percent, respectively, for the three intervals specified $(P<0.05)$. The high mortality rate in the first year in the 1961 to 1964 period is explained in part by the 8 percent perioperative mortality rate ( 4 of 51 patients) associated with the transthoracic epicardial operative approach available at the time. An additional patient died during a second epicardial implantation within the first year. No patient in this series died postoperatively when the transvenous approach was used.*

Mortality related to congestive failure and type of heart disease: The presence of congestive failure in the preimplantation period was also predictive of a higher mortality rate (Fig. 4). Those with definite heart failure in the preimplantation period had a survival rate of 73 and 49 percent at 2 and 5 years, respectively, whereas those free of congestive heart failure had a survival rate of 87 and 69 percent at these time intervals $(P<0.04)$. Other medical conditions did not, as independent variables, appear to affect survival significantly, except for those patients with a preimplantation diagnosis of malignant neoplasm $(P<0.001)$. Patients with systolic or diastolic hypertension and cerebrovascular disease had an insignificantly increased risk of death; the presence of diabetes mellitus, obesity, chronic obstructive lung disease, hyperlipidemia,

\footnotetext{
- At this institution in the same time period one patient with permanent pacing for sinus node disease died of an acute myocardial infarction and two patients with pacing for drug-refractory ventricular tachycardia died of recurrent arrhythmias within 14 days of transvenous pacemaker implantation; these patients were not included in our analysis because their indication for pacing was not $A-V$ block.
}

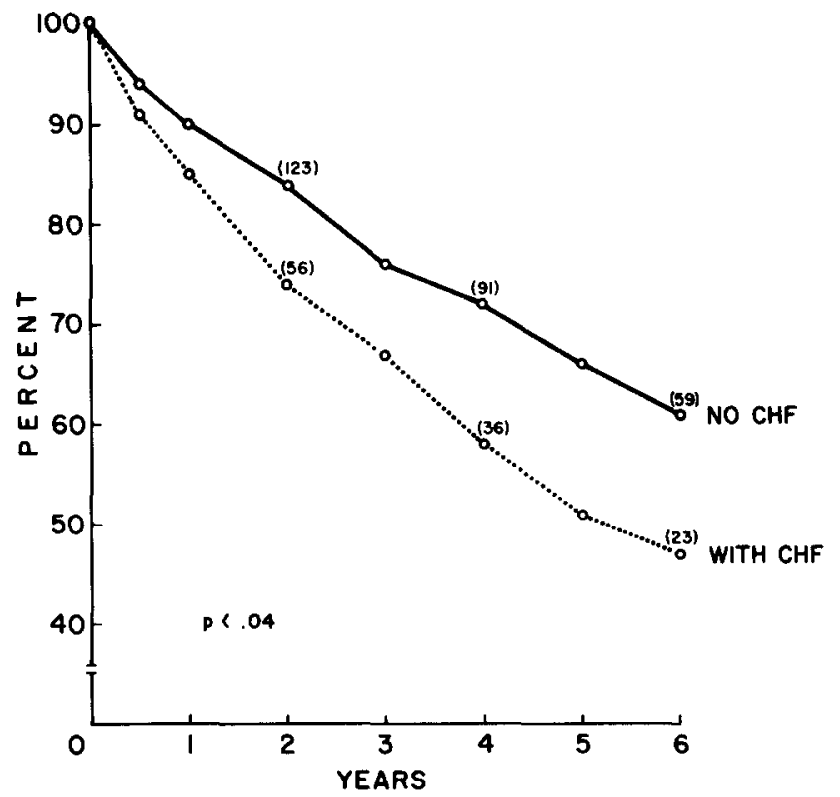

FIGURE 4. Survival after initial pacemaker implantation correlated with the presence of congestive heart failure (CHF) before implantation.

chronic renal disease or peripheral vascular disease did not increase the rate of late mortality.

The etiology of underlying heart disease did correlate with a greater late mortality (Fig. 5). Patients with ischemic or hypertensive heart disease had the poorest survival rate, only 40 percent living beyond 60 months. The 111 patients (45.5 percent) with "idiopathic" disease did far better; 87 and 72 percent survived 24 and 60 months, respectively. Patients with isolated aortic valve disease and rheumatic heart disease had an intermediate survival rate. There were two deaths by 42 months in the small group of seven patients with congenital heart disease, six of whom had iatrogenic complete heart block. Ten patients with apparent primary myocardial disease had a survival rate similar to that of the group with aortic valve disease. The relation between the etiology of underlying clinical heart disease and survival was highly significant $(P<0.002)$.

By combining variables it is possible, retrospectively, to group the patient population into those with a high (more than 85 percent) and very low (less than 25 percent) probability of survival at 5 years. Patients in the first category were less than 65 years old at initial implantation and had no history of myocardial infarction or congestive heart failure. Patients in the highest risk group were more than 74 years old, and had both angina pectoris and myocardial infarction before the initial implantation.

\section{Morbidity and Causes of Late Mortality}

Morbidity: During the course of follow-up, new major cardiovascular events were common. Twenty patients (9 percent) had an acute myocardial infarction, and 27 (11 percent) manifested congestive heart failure that had not been present before implantation. Central nervous system events (transient ischemic attacks, 


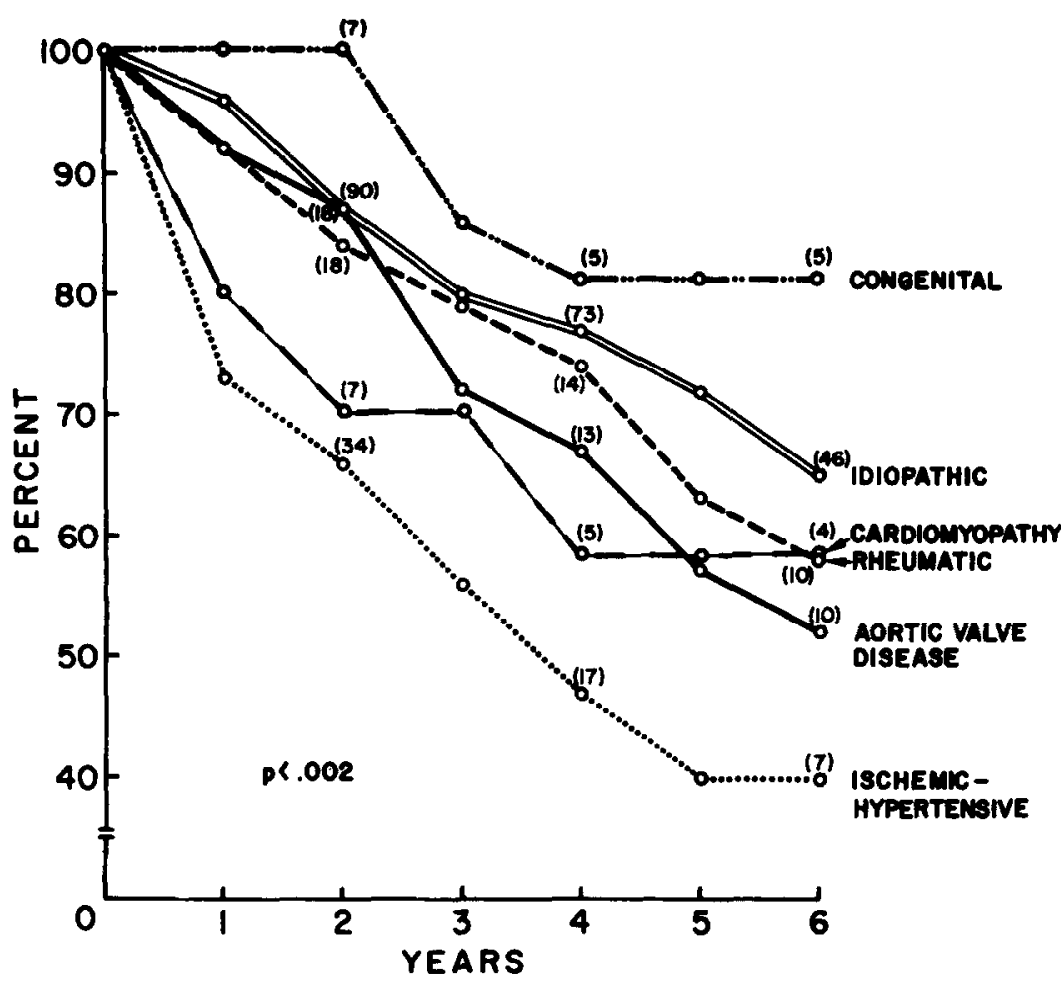

FIGURE 5. Correlation between survival and clinically apparent etiology of heart disease. Patients with ischemic-hypertensive disease did least well, 27 percent dying in the first year. completed stroke or progressive organic brain syndrome) were noted in 35 patients, and in 12 percent stroke was the primary cause of death (Table III). In addition, 19 patients ( 8 percent) had progressive azotemia, 15 had a new malignancy and 24 (10 percent) had a major pulmonary event (pneumonia, pulmonary insufficiency or embolism).

Causes of death: Forty-two percent of patients died of apparent cardiac causes (Table III); over half of these died suddenly (in 1 hour or less). Six percent died of definite or probable myocardial infarction. There was no correlation between the mode of death in those patients paced with asynchronous (VOO) versus synchronous (VVI) pulse generators at death, or in those from any time period.

\section{TABLE III}

\section{Causes of Death During Study Interval}

\begin{tabular}{|c|c|c|}
\hline & no. & Percent* \\
\hline Cardiac & 46 & 42 \\
\hline Sudden death ( $<1$ hour) & 24 & 20 \\
\hline Congestive heart failure & 15 & 14 \\
\hline Myocardial infarction & 6 & 6 \\
\hline Refractory ventricular tachycardia & 2 & \\
\hline Noncardiac & 34 & 31 \\
\hline Central nervous system & 13 & 12 \\
\hline Other (infection, pulmonary embolism, & 12 & 11 \\
\hline Unknown (unwitnessed, unspecified, & 21 & 19 \\
\hline unavailable data) & & \\
\hline Pacemaker failure & & \\
\hline $\begin{array}{l}\text { Perioperative } \\
\text { Total }\end{array}$ & $\begin{array}{r}5 \\
109\end{array}$ & $\begin{array}{r}5 \\
100\end{array}$ \\
\hline
\end{tabular}

" Expressed as percent of all deaths.
The exact cause of death.could not be established in 19 percent. Patients in this category frequently died with multiple illnesses in convalescent facilities and clinical data were not sufficient for accurate classification. Many of these patients were found dead, and no autopsy or medical examiner reports were available. From the limited information available on these latter patients, symptomatic cardiovascular disease appeared to be the most plausible cause of death in most instances. Autopsy and pulse generator inspection data were obtained in 21 percent of the 109 fatal cases; 36 percent of the patients died in a hospital, and 13 percent in a nursing or convalescent facility. Death was related to pacing unit malfunction in at least three patients. One patient died with pulmonary edema and the terminal electrocardiogram documented failure to capture and slow idioventricular rhythm. One patient died suddenly and the returned pulse generator had no output. Sudden death was associated with battery depletion in the third.

\section{Discussion}

Contribution of permanent cardiac pacing to increased survival of patients with A-V block: Several studies are available on the "natural history" of A-V block before the era of permanent pacing. ${ }^{22-30}$ Although the case selection and follow-up methods in these studies differ considerably, the frequently quoted mortality rate of approximately 50 percent within the first year after the diagnosis of complete A-V block seems reasonably accurate. Johansson ${ }^{25}$ called attention to the variations in mortality in the prepacing era in relation to age at onset and clinical setting of $A-V$ block. Differences in patient population, improvements in care 


\section{TABLE IV}

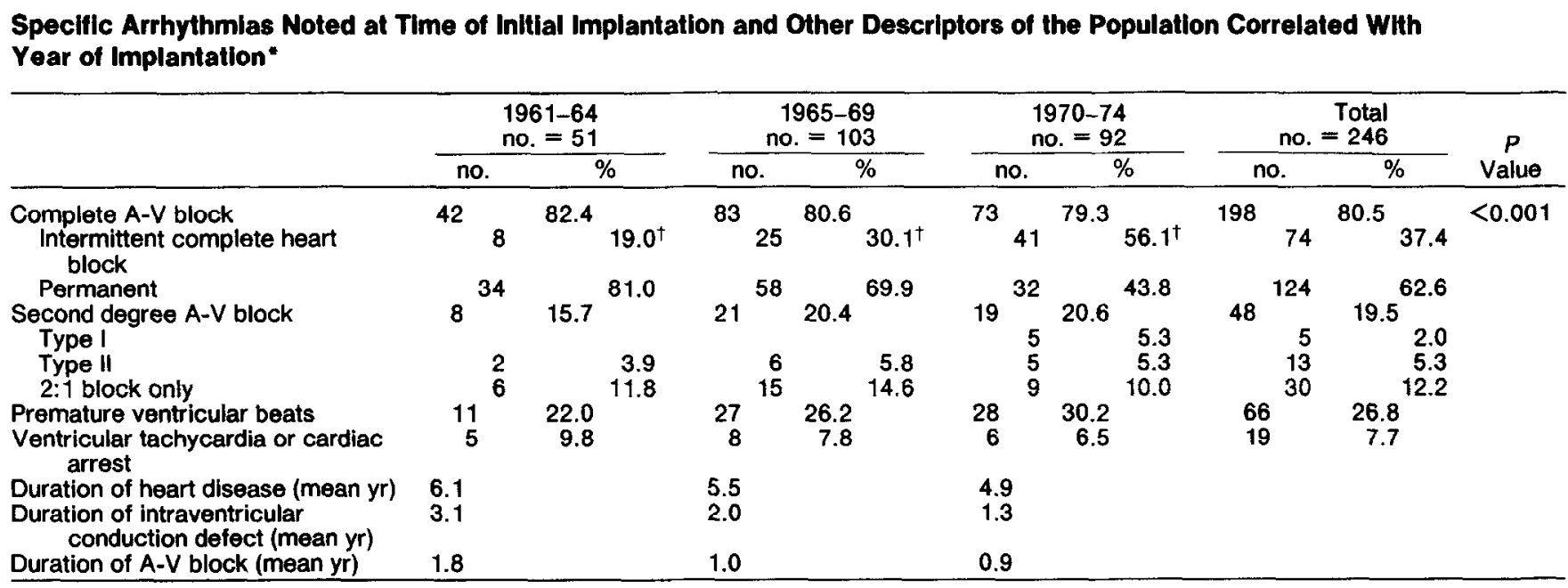

- Patients in the earlier years had symptomatic heart disease for a longer period of time than those selected later and had a higher frequency of permanent complete A-V block.

Expressed as a percent of those with complete $A-V$ block.

TABLE $V$

Etiology of Underlying Heart Disease at Entry as Correlated With Year of Initial Implantation*

\begin{tabular}{|c|c|c|c|c|c|c|c|c|}
\hline & \multicolumn{2}{|c|}{$\begin{array}{c}1961-64 \\
(\text { no. }=51)\end{array}$} & \multicolumn{2}{|c|}{$\begin{array}{c}1965-69 \\
(n o .=103)\end{array}$} & \multicolumn{2}{|c|}{$\begin{array}{c}1970-74 \\
\text { (no. }=92 \text { ) }\end{array}$} & \multicolumn{2}{|c|}{$\begin{array}{c}\text { Total } \\
\text { (no. }=246)\end{array}$} \\
\hline & no. & $\%$ & no. & $\%$ & no. & $\%$ & no. & $\%$ \\
\hline $\begin{array}{l}\text { Idiopathic } \\
\text { Ischemic-hypertensive } \\
\text { Rheumatic } \\
\text { Cardiomyopathy } \\
\text { Aortic valve disease } \\
\text { Congenital }\end{array}$ & $\begin{array}{r}24 \\
12 \\
8 \\
1 \\
2 \\
4\end{array}$ & $\begin{array}{r}47.1 \\
23.5 \\
15.7 \\
2.0 \\
3.9 \\
7.8\end{array}$ & $\begin{array}{r}53 \\
18 \\
9 \\
5 \\
5 \\
15 \\
3\end{array}$ & $\begin{array}{r}51.5 \\
17.5 \\
8.7 \\
4.9 \\
14.6 \\
2.9\end{array}$ & $\begin{array}{r}36 \\
37 \\
8 \\
4 \\
7 \\
-\end{array}$ & $\begin{array}{r}39.1 \\
40.2 \\
8.7 \\
4.3 \\
7.6 \\
-\end{array}$ & $\begin{array}{r}113 \\
67 \\
25 \\
10 \\
24 \\
7\end{array}$ & $\begin{array}{r}45.9 \\
27.2 \\
10.2 \\
4.1 \\
9.8 \\
2.8\end{array}$ \\
\hline
\end{tabular}

- See text for definitions. Six of the seven patients with congenital heart disease have iatrogenic complete heart block.

of congestive heart failure and other medical problems, the introduction of palliative operative procedures for congenital and valvular heart disease as well as improved methods of diagnosis (possibly, therefore, including patients at an earlier stage of their disease) prevent accurate comparison between patients with symptomatic advanced second degree or complete $\mathrm{A}-\mathrm{V}$ block now treated with permanent pacing and "control" subjects observed in the 1940 to 1960 period. Even after these limitations are acknowledged, the improvement in survival in current series is so dramatic that there is little doubt that pacing has drastically increased survival of patients with this arrhythmia.

Nevertheless, patients with permanent pacemakers implanted for A-V block do continue to experience cardiovascular morbidity and mortality and have a significantly higher mortality rate than the general U.S. population. Although patients with conduction disturbances are found in every age group, this population is, in general, an elderly group with a high prevalence rate of chronic diseases including malignant neoplasm, obstructive lung disease, diabetes mellitus, peripheral and cerebrovascular disease and renal failure. Pro- gression of cardiovascular disease, including recurrent or new congestive failure, myocardial infarction and stroke as well as sudden death, account for over half and probably three quarters of all late deaths in these patients. In addition, age, antecedent ischemic heart disease and congestive heart failure before permanent pacing are important predictive factors for early mortality after successful pacemaker implantation. It is unlikely that differences in patient selection played a significant role in the higher patient mortality rate in the early time period (Table IV). Although patients in the 1961 to 1964 period had a greater prevalence of syncope, fixed complete A-V block and a slightly longer duration of symptoms than those patients in the later periods, their age and the prevalence rate of congestive heart failure, angina pectoris and prior myocardial infarction were no higher (Table I). For example, 35 percent of the patients in the earlier time period had A-V block or syncope for more than 1 year, whereas only 20 percent of those in the last time period had symptoms of that duration. In fact, the prevalence of ischemic heart disease and congestive heart failure was slightly greater in the later years (Tables IV and V), perhaps 
reflecting a trend toward the use of pacing in patients who might have been excluded in the earlier time period because of the need for a general anesthetic and thoracotomy. Elimination of perioperative mortality associated with general anesthesia as well as improved medical and surgical methods of treatment of cardiovascular disease have probably contributed to this improvement in survival.

Role of pacemaker failure in late deaths: Between 1961 and 1967 all pacing was performed with asynchronous (VOO) ${ }^{31}$ pulse generators whose reliability and longevity were inferior to those of currently available models. ${ }^{10}$ Pacing system failure appeared to contribute to very few deaths in previously reported series. ${ }^{1,32-39}$ In our group sudden death was no more common in the early period and was not more common in patients paced with asynchronous (VOO) units. Because unwitnessed death 16,17 and deaths due to unknown causes constitute a relatively large part (19 percent in our series) of all deaths in patients undergoing pacing and because the pulse generator and pacing lead could be inspected in only a few of those who died suddenly, some uncertainty must remain concerning the role of the pacing system in these deaths. This question can be resolved only by a systematic complete examination of a selected group of pacing systems after death in patients who die suddenly or of unknown causes.

Mortality findings in our series are similar to those previously reported by others. ${ }^{1-3,32-39}$ The somewhat better overall survival rate compared with that of some other series may be attributed to a slightly younger patient population, a lesser prevalence of prior acute myocardial infarction and the later period from which the patients were drawn. As in other studies, mortality appears to be greatest in the first year after the initial pacemaker implantation.

Role of congestive failure in early mortality and indication for sequential atrial pacing: Congestive heart failure as a predictor of earlier patient death deserves special mention. Numerous studies have documented improved hemodynamics and disappearance of signs and symptoms of congestive failure after permanent pacing. ${ }^{40}$ However, persistent cardiomegaly, ${ }^{25}$ continued dependence on digitalis and diuretic agents, and the failure of permanent pacemaker implantation to alleviate congestive heart failure in some patients is well documented. ${ }^{41}$ Recurrent or new heart failure was common in our series. The rate of death was significantly greater for patients with definite congestive heart failure before implantation and, in fact, the mortality rate of patients with congestive heart failure and $A-V$ block after pacing in our series closely approximates that of the Framingham study patients with heart failure without $\mathrm{A}-\mathrm{V}$ block. ${ }^{21}$ Heart failure that accompanies $\mathrm{A}-\mathrm{V}$ block is often only partially due to the slow rate itself, and impaired ventricular function in patients after permanent ventricular pacing is not uncommon. There may be a distinct role for A-V synchronous (VAT) or sequential pacing (DVI) in patients with maintained atrial function in order to take full advantage of the atrial contribution to cardiac output in patients with A-V block. Studies by Leinbach et al. ${ }^{42}$ and others have shown a 20 percent improvement in resting cardiac output with this mode of pacing compared with ventricular pacing alone. The development of improved transvenous atrial electrodes will be necessary to test the possibility of whether such pacing will be beneficial to enough patients to warrant its widespread use in those with persistent or severe congestive failure and A-V block.

Implications: In our study sudden death was the most common mode of death in the population undergoing pacing for A-V block. Preliminary data indicate that ventricular arrhythmias of a serious nature are common in such patients (unpublished data). However, at this juncture there is little evidence to indicate that available antiarrhythmic agents decrease the frequency of complex ventricular arrhythmias consistently in this population or that they will decrease the incidence of late sudden death.

Several longitudinal studies have demonstrated that patients undergoing pacing for A-V block and probably for sinus node disease as well ${ }^{43,44}$ have a high mortality rate in the first 5 years after initial pacemaker implantation. Certain groups of these patients appear to have an especially poor survival rate, including those with impaired left ventricular function before implantation, those over age 74 at initial implantation and those with a prior history of ischemic heart disease.

\section{Acknowledgment}

We gratefully acknowledge the assistance of Drs. Park W. Willis and Leon Ostrander for their critical review of the manuscript; Lois $\mathrm{M}$. Verbrugge, $\mathrm{PhD}$ for statistical consultation; and Drs. Richard Judge, Michael James, Elaine J. Alpert and John C. Sennish for review of medical records and patient follow-up.

\section{References}

1. Bernsteln V, Rotem CE, Perelz Dl: Permanent pacemakers: eight year follow-up study. Ann Intern Med 74:361-369, 1971

2. Amikam S, Lemer J, Roglun N, et al: Long term survival of elderly patients after pacemaker implantation. Am Heart J 9:445-449, 1976

3. Seremetis MG, de Guzman VC, Lyons WS, et al: Cardiac pacemakers: clinical experience with 289 patients. Am Heart J 85: 739-748, 1973

4. Davidson DM, Braak CA, Preston TA, et al: Permanent ventricular pacing: effect on long term survival, congestive heart failure, and subsequent myocardial infarction and stroke. Ann Intern Med 77:345-351, 1972

5. Judge RD, Preston TA, Lelninger BJ, et al: Clinical experience and problems encountered with an implantable pacemaker. $J$ Thorac Cardiovasc Surg 50:849-856, 862-867, 1965

6. Morrls JD, Judge RD: Myocardial electrode implantations: indications and advantages. Ann NY Acad Sci 167:987-994, 1969

7. Preston TA, Judge RD, Lucchesl BR, ot al: Myocardial threshold 
in patients with artificial pacemakers. Am J Cardiol 18:83-89, 1966

8. Preston TA, Judge RD: High myocardial threshold to an artificial pacemaker. Report of a fatal case. N Engl J Med 276:798 799, 1967

9. Preston TA, Judge RD, Bowers DL, et al: Measurement of pacemaker performance. Am Heart J 71:92-99, 1966

10. Kahn DR, Kirsh MM, Vathayanon S, et al: Long term evaluation of the General Electric cardiac pacemaker. Thorax 25:267-269, 1970

11. Judge RD, Wlison WS, Slegel JH: Hemodynamic studies on patients with implanted cardiac pacemakers. N Engl J Med 270: 1391-1394, 1964

12. Gehan EA: Estimating survival functions from the life table. J Chronic DIs 21:629-644, 1969

13. Cutler SJ, Ederer F: Maximum utilization of the Life Table Method in analyzing survival. J Chronic Dis 8:699-712, 1958

14. Fox DJ, Guire KE: Documentation for MIDAS (Michigan Interactive Data Analysis System), second edition (revised), 1974. Statistical Research Laboratory, University of Michigan, Ann Arbor, Michigan

15. Heillbrun LK: Documentation of IGSAS (Interactive Graphics Survival Analysis System), second edition, 1975. Dept of Biostatistics, School of Public Health, University of Michigan, Ann Arbor, Michigan

16. Breslow N: A generalized Kruskal-Wallis Test for comparing $K$ samples subject to unequal patterns of censorship. Biometrika 57:579-594, 1970

17. US Department of Health, Education and Welfare: Vital Statistics of the United States, 1962-1973. II, Part A, Section 5. Public Health Service, Washington, DC, US Government Printing Office, 1962-1973

18. National Center for Health Statistics, United States Life Tables, 1969-1971, Vol I, no I, DHEW Publication 75-1150. US Dept of Health, Education and Welfare, Rockville, Maryland, 1975

19. Simon AB, Alonzo A: Sudden death in non-hospitalized cardiac patients. Arch Intern Med 132:163-170, 1973

20. Kuller L: Sudden and unexpected nontraumatic deaths in adults. A review of epidemiological and clinical studies. J Chronic Dis 19:1165-1192, 1966

21. McKee PA, Castelli WP, McNamara PM, et al: The natural history of congestive heart failure: the Framingham Study. N Engl J Med 285:1441-1446, 1971

22. Rowe JC, White PD: Complete heart block: a follow-up study. Ann Intern Med 49:260-275, 1957

23. Penton GB, Miller H, Levine SA: Some clinical features of complete heart block. Circulation 13:801-824, 1956

24. Friedberg CK, Donoso E, Stein WG: Non-surgical acquired heart block. Ann NY Acad Sci 111:935-847, 1964

25. Johansson BW: Complete heart block. A clinical, hemodynamic and pharmacological study in patients with and without an artificial pacemaker. Acta Med Scand 180:Suppl 451:1-127, 1966

26. Curd CW Jr, Dennis DW, Jordan J, et al: Etiology of atrioventricular block: a study of its relevance to prognosis and pacemaker therapy. Cardiovasc Res Cent Bull 1:63-69, 1963

27. Campbell M: Complete heart block. Br Heart J 6:69-92, 1944

28. Wright JC, Hejtmanclk MR, Herrmann GR, et al: A clinical study of complete heart block. Am Heart J 52:369-378, 1956

29. Cosby RS, Cafierhy EA, Lau FYK, et al: Electrocardiographic and clinical features in the prognosis of complete heart block (abstr). Am J Cardiol 15:128, 1965 (see also Lau SH, et al: Circulation 32:Suppl II:Il-132, 1965)

30. Pader E, Levy H: Clinical and electrocardiographic studies in complete heart block. J Chronic Dis 19:1101 1122, 1966

31. Parsonnet V, Furman S, Smyth NPD: Implantable cardiac pacemakers, status report and resource guldeline: pacemaker study group. Circulation 50:A-21-A-33, 1974

32. Zlon MM, Marchand PE, Obel IWP: Long term prognosis after cardiac pacing in atrioventricular block. Br Heart J 35:357-364, 1973

33. Sowton E, Flores J: Natural history of pacemaker patients. Bull NY Acad Med 47:999-1010, 1971

34. Chardack WM, Gage AA, Federico AJ, ot al: Five years' clinical experience with an implantable pacemaker: an appraisal. Surgery 58:915-922, 1965

35. Johansson BW: Longevity in complete heart block. Ann NY Acad Sci 167:1031-1037, 1969

36. Amlkam S, Roglun N, Mankiewicz W, et al: 150 pacemaker implantations. J Isr Med Assoc 87:439-444, 1974

37. Siddons H: Deaths in long term paced patients. Br Heart $\mathrm{J} 36$ 1201-1209, 1974

38. Obel IWP, Marchard PE, Scott-Mller RW: Cardiac pacemaking: experience with the first 120 patients treated in Johannesburg. $S$ Afr Med J 46:2002-2006, 1972

39. Harthorne JW, Leinbach RC, Sanders CA, et al: Clinical results of transvenous pacing. Ann NY Acad Sci 167:1008-1015, 1969

40. Sowton E: Haemodynamic studies in patients with artificial pacemakers. Br Heart J 26:737-746, 1964

41. Adoph RJ, Holmes JC, Fukusumi H: Hemodynamic studies in patients with chronically implanted pacemakers. Am Heart J 76: 830-838, 1968

42. Leinbach RC, Chamberlain DA, Kastor JA, et al: A comparison of the hemodynamic effects of ventrlcular and sequentlal $A-V$ pacing in patients with heart block. Am Heart $\mathrm{J} 78: 502-508$, 1969

43. Wohl AJ, Laborde J, Atkins JM, et al: Prognosis of patients permanently paced for sick sinus syndrome. Arch Intern Med 136: 406-408, 1976

44. Frueham CT, Heneghan WF, Eich RH: Late mortality of patients with sick sinus syndrome (abstr). Circulation 53, 54:Suppl 11:11-77, 1976 